Claremont Colleges

Scholarship@ Claremont

All HMC Faculty Publications and Research

HMC Faculty Scholarship

$11-1-1998$

\title{
An Ab Initio Study of Specific Solvent Effects on the Electronic Coupling Element in Electron Transfer Reactions
}

Thomas M. Henderson '98

Harvey Mudd College

Robert J. Cave

Harvey Mudd College

\section{Recommended Citation}

An ab initio study of specific solvent effects on the electronic coupling element in electron transfer reactions. Thomas M. Henderson and Robert J. Cave, J. Chem. Phys. 109, 7414 (1998), DOI:10.1063/1.477403

This Article is brought to you for free and open access by the HMC Faculty Scholarship at Scholarship @ Claremont. It has been accepted for inclusion in All HMC Faculty Publications and Research by an authorized administrator of Scholarship @ Claremont. For more information, please contact scholarship@cuc.claremont.edu. 


\title{
An ab initio study of specific solvent effects on the electronic coupling element in electron transfer reactions
}

\author{
Thomas M. Henderson and Robert J. Cave ${ }^{\mathrm{a})}$ \\ Department of Chemistry, Harvey Mudd College, Claremont, California 91711
}

(Received 3 June 1998; accepted 28 July 1998)

\begin{abstract}
Specific solvent effects on the electronic coupling element for electron transfer are examined using two model donor-acceptor systems $\left(\mathrm{Zn}_{2}^{+}\right.$and $\left.\mathrm{Li}_{2}^{+}\right)$and several model "solvent" species $\left(\mathrm{He}, \mathrm{Ne}, \mathrm{H}_{2} \mathrm{O}\right.$, and $\mathrm{NH}_{3}$ ). The effects are evaluated relative to the given donor-acceptor pair without solvent present. The electronic coupling element $\left(H_{a b}\right)$ is found to depend strongly on the identity of the intervening solvent, with $\mathrm{He}$ atoms decreasing $H_{a b}$, whereas $\mathrm{H}_{2} \mathrm{O}$ and $\mathrm{NH}_{3}$ significantly increase $H_{a b}$. The distance dependence (essentially exponential decay) is weakly affected by a single intervening solvent atom-molecule. However, when the donor-acceptor distance increases in concert with addition of successively greater numbers of solvent species, the decay with distance of $H_{a b}$ is altered appreciably. Effects due to varying the orientation of molecular solvent are found, somewhat surprisingly, to be quite modest. (C) 1998 American Institute of Physics. [S0021-9606(98)30141-5]
\end{abstract}

\section{INTRODUCTION}

Solvent often plays an important role in controlling the rate of electron transfer $(e t)$ between donor $(D)$ and acceptor (A) sites. $^{1-4}$ The work of Marcus, ${ }^{5}$ Hush, ${ }^{6}$ Levich and Dogonadze, ${ }^{7}$ and others ${ }^{8}$ has shown the important role solvent plays in determining the rate of reaction via dielectric response to the transferring charge. In the classical or semiclassical theories, ${ }^{5,6}$ the solvent is treated as a dielectric continuum with at least two response times (one slow, one fast), and one obtains the familiar Marcus-Hush quadratic expression for the free-energy of activation which is dependent on the solvent reorganization energy, $\lambda_{0}$. More recent theories $^{9-11}$ and experiments ${ }^{12}$ have revealed that the diffusive motion of the solvent can also play a significant role in controlling the rate of electron transfer, especially for very fast reactions.

Previous work has also suggested that intervening solvent can alter the electronic coupling ${ }^{13-21}$ between donor and acceptor sites via a superexchange mechanism. ${ }^{22-25}$ The concept of superexchange coupling in et has its roots in the work of Halpern and Orgel, ${ }^{23}$ McConnell, $^{24}$ and Larsson ${ }^{25}$ and arises physically due to weak interactions of the $D$ and/or $A$ diabatic states with localized or delocalized states of the intervening medium. In the present article we use the term "superexchange", to indicate any electronic interactions (one-electron or many-body) between $D$ or $A$ and the intervening medium that alter the electronic coupling between donor and acceptor. ${ }^{22}$ A large body of work has appeared which has examined such effects when the intervening medium is a contiguously bonded network also bonded to $D$ and $A .^{18,22,26-32}$ Detailed information has been obtained about the rate of decay of the coupling with distance (or number of bonds) and its dependence on intervening medium. Work has

a) Author to whom correspondence should be addressed. also focused on interference effects between two or more "pathways" from $D$ to $A$ along the bridging medium. ${ }^{15,22,26-29}$ The effects due to solvent between $D$ and $A$ have also been examined. The work of Miller and co-workers ${ }^{13}$ provided the first experimental evidence that solvent could could play a significant role in mediating the electronic coupling. Recent work has shown that "throughsolvent" superexchange effects may be the predominant means of mediating the electronic coupling in some linked $D-A$ systems. ${ }^{14,16}$ In addition, Gould et al. ${ }^{17}$ studied $e t$ between alkyl-substituted benzenes and cyano-substituted anthracenes and found evidence for possible solvent-separated radical-ion pairs. Here too the solvent may have a significant effect on the electronic coupling between donor and acceptor.

The purpose of the current article is to initiate a detailed $a b$ initio quantum chemical study of the orientation-, distance-, and energy-dependence of solvent effects on the electronic coupling element for electron transfer. In semiclassical theories the rate expression for nonadiabatic et in the high-temperature limit is of the form ${ }^{33}$

$$
k_{e t}=\frac{2\left|H_{A B}\right|^{2}}{h}\left(\frac{\pi^{3}}{\lambda R T}\right)^{1 / 2} \exp \left(-\Delta G^{*} / R T\right),
$$

with $\lambda$ the total reorganization energy and $\Delta G^{*}$ the free energy of activation. The derivation of Eq. (1) is based on a Landau-Zener treatment ${ }^{34}$ and as such requires the value of $H_{a b}$ at the minimum energy point along the crossing seam of the diabatic surfaces involved in the reaction, at which point $H_{a b}=\Delta E_{\text {adiabatic }} / 2$. In fully quantum mechanical treatments ${ }^{7,8}$ of nonadiabatic et $H_{a b}$ is the interaction energy between donor and acceptor diabatic states at any nuclear geometry, not merely that of the crossing seam. However, most quantum mechanical theories invoke the Condon approximation ${ }^{35}$ (that is, $H_{a b}$ is weakly dependent upon nuclear coordinates), generally choosing the value of $H_{a b}$ as in semiclassical theo- 
ries. The values of $H_{a b}$ that we obtain are not, in general, those along the crossing seam of the two diabatic surfaces, hence the donor and acceptor diabatic state energies are not equal. The systems studied here have many independent coordiates and the search for the crossing seam, let alone the minimum energy point along it, is not feasible for the systems examined. However, the methods employed allow the calculation of $H_{a b}$ at any nuclear geometry and the Condon approximation suggests the $H_{a b}$ values obtained at the nuclear geometries we use should be similar to those along the crossing seam. In a series of test calculations (see below) we examine the validity of the Condon approximation and find it holds reasonably well in these systems.

Given the size limitations imposed by use of ab initio methods the systems considered are restricted to $D, A$, and a small number of weakly interacting solvent atomsmolecules. As a result one might consider use of the term solvent inappropriate when applied here. Indeed, the important energetic effects due to dielectric polarization and possible ligation of the $D$ and $A$ species are missing in such a treatment. However, the superexchange interactions which are important in altering the electronic coupling element should arise largely from solvent between $D$ and $A,{ }^{16,18,36}$ and neglect of the solvent outside the line of centers of the $D A$ pair will not qualitatively affect the coupling. The definition of solvent $(S)$ used here is thus any species that is weakly interacting with $D$ and $A$, either because of intrinsically weak bonding or due to sufficient $D-S$ ( or $A-S$ ) distance to lead to a weak interaction.

In the present study we use $\mathrm{Zn}_{2}^{+}$and $\mathrm{Li}_{2}^{+}$as model donor-acceptor pairs. They are particularly simple from an electronic structural viewpoint, but $\mathrm{Zn}_{2}^{+}$has been well studied in the absence of solvent ${ }^{37-39}$ in the ground and several low-lying excited states so that the effects of the solvents used here can be accurately assessed. $\mathrm{Li}_{2}^{+}$is an extremely simple system, which, when compared with $\mathrm{Zn}_{2}^{+}$, allows one to examine the sensitivity of solvent effects to the energy of the donor or acceptor states involved in the process. The solvents used include $\mathrm{He}, \mathrm{Ne}, \mathrm{H}_{2} \mathrm{O}$, and $\mathrm{NH}_{3}$ which allow further assessment of energetic effects [variation in ionization potential (IP) and electron affinity (EA)], as well as possible orientation effects in the two molecular cases. Using these models for $D, S$, and $A$ the distance dependence of $H_{a b}$ as a function of $D-A$ separation and $D-S$ separation is examined. Finally, the decay of $H_{a b}$ with $D-A$ distance is examined when increasing numbers of intervening water molecules or He atoms are included.

The electronic coupling element is evaluated using the recently developed generalized Mulliken-Hush (GMH) approach. ${ }^{37,38}$ The GMH method can be used for ground- or excited-state calculations, for the simultaneous evaluation of the electronic coupling between several states (i.e., beyond the two-state approximation), at any nuclear geometry (not merely at the geometry corresponding to the crossing point of the pair of relevant diabatic surfaces). It has been compared with other approaches (block diagonalization, ${ }^{38,40}$ half the minimum energy splitting) and found to be in good agreement.

The rest of the article is organized as follows. In Sec. II the methods used to calculate the electronic wave functions and $H_{a b}$ are presented and the basis sets which were used are discussed in detail. In Sec. III results are presented. Section IV contains a discussion of the results, while conclusions are presented in Sec. V.

\section{THEORETICAL METHODS}

\section{A. Wave functions}

All systems were described using complete active space self-consistent field (CASSCF) wave functions $;{ }^{41}$ the calculations were performed using MOLCAS $3 .{ }^{42}$ Since more than one state was sought (a minimum of two, in order to describe the initial and final states in the et process) the stateaveraged $\mathrm{CASSCF}^{41}$ (SA/CASSCF) method was used here. The SA/CASSCF wave functions are denoted $n / m$ $p \mathrm{SA} / \mathrm{CASSCF}$, where $n$ and $m$ are the number of active electrons and orbitals, respectively, and $p$ is the number of states used in the state-averaging process. In previous studies on $\mathrm{Zn}_{2}^{+}$with the GMH method, ${ }^{37,38}$ we have used wave functions separately optimized for each adiabatic state of interest and found little change in $H_{a b}$ relative to SA/CASSCF results. Similar agreement is expected here. In a few cases for $\mathrm{Zn}_{2}^{+}$, four state SA/CASSCF calculations (4SA/CASSCF) have been performed, including states in the averaging process that correlate at large $\mathrm{Zn}-\mathrm{Zn}$ distances with the Valence-Bond-type configurations ${ }^{1} S(\mathrm{Zn})-{ }^{2} S\left(\mathrm{Zn}^{+}\right)$, ${ }^{2} S\left(\mathrm{Zn}^{+}\right)-{ }^{1} S(\mathrm{Zn}), \quad{ }^{3} P(\mathrm{Zn})-{ }^{2} S\left(\mathrm{Zn}^{+}\right), \quad$ and $\quad{ }^{2} S\left(\mathrm{Zn}^{+}\right)$ $-{ }^{3} P(\mathrm{Zn})$. However, in most cases we are concerned with electron transfer involving ground-state donor and acceptor, and in these cases a 2SA/CASSCF calculation was performed [including states correlating with ${ }^{1} S(\mathrm{Zn})-{ }^{2} S\left(\mathrm{Zn}^{+}\right)$, $\left.{ }^{2} S\left(\mathrm{Zn}^{+}\right)-{ }^{1} S(\mathrm{Zn})\right]$. For $\mathrm{Li}_{2}^{+}$only the two lowest states of the system were considered [correlating at large separation with ${ }^{2} S(\mathrm{Li})-{ }^{1} S\left(\mathrm{Li}^{+}\right)$and $\left.{ }^{1} S\left(\mathrm{Li}^{+}\right)-{ }^{2} S(\mathrm{Li})\right]$.

\section{B. One-electron basis sets}

A variety of one-electron basis sets were used in the present study:

(i) Zn: The basis set was built upon the Wachters $(14 s, 9 p, 5 d)$ basis $^{43}$ contracted using a Raffenetti scheme ${ }^{44}$ based on the coefficients provided in Ref. 43. This yields four $s$ functions, two $p$ functions, and one $d$ function. The two most diffuse $s$ basis functions and the most diffuse $p$ and $d$ functions of the original basis set were also added as additional uncontracted functions. Finally, diffuse $s(0.3960,0.015), p(0.310,0.120,0.047,0.018)$, and $d(0.155)$ functions were added to the basis. This basis set is referred to below as $\mathrm{Zn}$ basis $a$, and is the basis set employed for $\mathrm{Zn}$ unless otherwise specified. In some cases extended basis sets were used, built on basis set $a$. Zinc basis $b$ was constructed from basis $a$ by adding additional $s(0.0044), p(0.0069)$, and $d(0.042)$ functions. Zinc basis $c$ was used to examine basis set completeness questions for $H_{a b}$ and contained all the functions in basis $b$, with an additional $s, p$, and $d$ function based on even tempered ${ }^{45}$ extension using the last two functions in each angular momentum. Tests with basis sets $b$ and $c$ in the absence of solvent molecules yield ground-state coupling elements differing by at most $12 \%$ at a separation of 10 
$\AA$ compared to results with basis set $a$, while similar augmentations in the presence of solvent in the course of the current study yielded even smaller differences.

For $\mathrm{Li}, \mathrm{He}, \mathrm{Ne}, \mathrm{H}, \mathrm{O}$, and $\mathrm{N}$, members of the family of atomic natural orbital (ANO) basis sets of Widmark et al. ${ }^{46}$ were used:

(ii) Li: The primitive set is $(14 s, 9 p, 4 d, 3 f) .{ }^{46} H_{a b}$ values for $\mathrm{Li}_{2}^{+}$were compared for several contracted basis sets and the ANO contraction $(5 s, 3 p, 2 d)$ was found to yield results in good agreement with those obtained using more extended basis sets [up to $(7 s, 6 p, 4 d, 3 f)$ ]. Even tempered extension ${ }^{45}$ of the primitive Gaussian basis was also found to have little effect on $H_{a b}$ over the range of 6-12 $⿱$. Thus, in all calculations reported here the $(5 s, 3 p, 2 d)$ ANO basis set was used.

(iii) He: The primitive basis set is $(9 s, 4 p, 3 d) .{ }^{46}$ Several ANO contractions were examined for $\mathrm{He}$ as solvent and the $(5 s, 2 p)$ ANO basis was found to yield $H_{a b}$ values for $[\mathrm{Zn}-\mathrm{He}-\mathrm{Zn}]^{+}$in good agreement with those obtained from larger contracted basis sets [up to $(7 s, 4 p, 3 d)$ ].

(iv) Ne: The primitive basis set is $(14 s, 9 p, 4 d) .{ }^{46}$ The ANO contraction $(6 s, 4 p, 2 d)$ was used for all calculations reported here, but tests with a $(5 s, 3 p, 1 d)$ contraction produced $H_{a b}$ values for [ $\left.\mathrm{Zn}-\mathrm{Ne}-\mathrm{Zn}\right]^{+}$in excellent agreement with those from the larger ANO set, suggesting that the results were converged with respect to contraction scheme.

(v) $\mathrm{H}_{2} \mathrm{O}, \mathrm{NH}_{3}$ : The water and ammonia molecules were assigned their experimental equilibrium structures ${ }^{47,48}$ (water: $R_{\mathrm{OH}}=0.957 \AA, \quad \Varangle=104.5^{\circ}$ ), (ammonia: $R_{\mathrm{NH}}=1.012 \AA$, $\left.\Varangle=106.7^{\circ}\right)$. The primitive basis sets for $\mathrm{O}$ and $\mathrm{N}$ were $(14 s, 9 p, 4 d) ;{ }^{46}$ the primitive set for $\mathrm{H}$ was $(8 s, 4 p)$. In most cases a $(4 s, 2 p)$ ANO contraction was used for $\mathrm{O}$ or $\mathrm{N}$, with a (2s) ANO contraction for $\mathrm{H}$, in test calculations with water as solvent, larger ANO contracted sets were used [up to $(7 s, 4 p, 3 d)$ for $\mathrm{O}$ and $(5 s, 2 p)$ for $\mathrm{H}]$, yielding values of $H_{a b}$ for $\left[\mathrm{Zn}-\mathrm{H}_{2} \mathrm{O}-\mathrm{Zn}\right]^{+}$within $10 \%$ of those obtained with the water $(4 s, 2 p / 2 s)$ ANO contracted basis. Augmentation of the water primitive basis set (even-tempered extension) in the $s$ and $p$ spaces for $\mathrm{O}$ and $s$ space for $\mathrm{H}$ also produced modest changes in $H_{a b}(<10 \%)$ relative to the results obtained in the contracted $(4 s, 2 p / 2 s)$ basis.

Given that the systems examined below are not in closecontact (i.e., weakly interacting) the description of the longrange behavior of the wave functions is important in obtaining converged electronic coupling elements. This is to be distinguished from the basis set dependence of $H_{a b}$ for longrange $e t$ in covalently bonded systems,${ }^{49}$ where it has been shown that modest basis sets can yield converged results, due to the relatively large overlap of atomic orbitals on adjacent atoms. For weakly interacting systems one possible concern would be that basis set superposition errors $(B S S E)^{50}$ (due to basis set incompleteness) might have a significant effect on the value of $H_{a b}$. A series of test calculations were thus performed to assess such effects on the electronic coupling in $\mathrm{Zn}_{2}^{+}$. Using $\mathrm{Zn}$ basis set $a, H_{a b}$ for ground-state $e t$ was first calculated at $R_{\mathrm{ZnZn}}=6,8$, and $10 \AA$. The electronic coupling was then recalculated at the same distances, having placed the $(4 s, 2 p / 2 s)$ water basis set at various positions between the two $\mathrm{Zn}$ atoms. The $\mathrm{O}$ and $\mathrm{H}$ basis functions were placed in the water $C_{2 v}$ orientation (see below) at the positions they would have occupied had a water been present (note, however, that no water nuclei or electrons were present in these calculations) and the electronic coupling for $\mathrm{Zn}_{2}^{+}$was recalculated in this larger basis set to assess BSSE on $H_{a b}$. It was found that at 6 and $8 \AA$ separation the electronic coupling element for ground-state $e t$ differed by less than $1 \%$ from the results without the water basis present, while at $10 \AA$ separation the coupling differed by at most $11 \%$. Similar variation at large $R_{\mathrm{ZnZn}}$ was observed in the progression from $\mathrm{Zn}$ basis set $a$ to basis set $c$ at large $R_{\mathrm{ZnZn}}$ and is much smaller than the changes in $H_{a b}$ obtained with solvent present (see below). It is interesting to note that the BSSE (estimated using the counterpoise correction ${ }^{51}$ ) for $\mathrm{Zn}_{2}^{+}$with the water basis set present is $\sim 10^{-5}$ hartrees at all separations. This is significantly smaller than $H_{a b}$ at 6 and $8 \AA$, but is a factor of 2 larger than $H_{a b}$ at $10 \AA$. Thus even in the presence of reasonably large BSSE (compared to $H_{a b}$ ) one can still extract accurate values for $H_{a b}$ for weakly interacting systems. These results indicate that we can assign the changes in electronic coupling observed in the presence of solvent in what follows to superexchange-type effects, rather than BSSE.

\section{Method for the calculation of $\boldsymbol{H}_{a b}$}

The method used in the calculation of the electronic coupling element was the generalized Mulliken-Hush (GMH) method. ${ }^{37,38}$ The GMH method is based on the original Mulliken-Hush ${ }^{52}$ treatment for charge transfer transitions; the method has been presented in detail in Refs. 37 and 38, and only a brief discussion is given here.

In an electron transfer process, it is natural to assume there are two or more sites at which the electron may be localized, with associated diabatic (localized) states characterizing the total electronic wave function at each distinct site. The GMH method defines diabatic states as those states having zero off-diagonal intersite (parallel) ${ }^{53}$ dipole moment matrix elements. Thus, the transformation that diagonalizes the adiabatic (parallel) dipole moment matrix is a transformation to the GMH diabatic states. When the same transformation is applied to the adiabatic (diagonal) Hamiltonian matrix, one obtains diabatic coupling elements $\left(H_{a b}\right)$. For systems with two or more states of interest localized at a given site (e.g., ground and one or more excited states) the diagonalization of the entire dipole moment matrix is not justified by the initial Mulliken-Hush ${ }^{52}$ assumption concerning the nature of charge-transfer states. In this case, the GMH method assumes that diabatic states localized on a given site are weakly perturbed and Hamiltonian matrix elements between these states should be zero. Rediagonalization of the transformed Hamiltonian over local site blocks (and analogous transformation of the diabatic dipole moment matrix over local site blocks) yields the locally adiabatic GMH states ${ }^{37,38}$ (which are nevertheless diabatic in the intersite sense).

In order to compactly indicate specific et processes, they will at times be described in terms of the orbitals from which the electron originates and to which the electron transfers. 


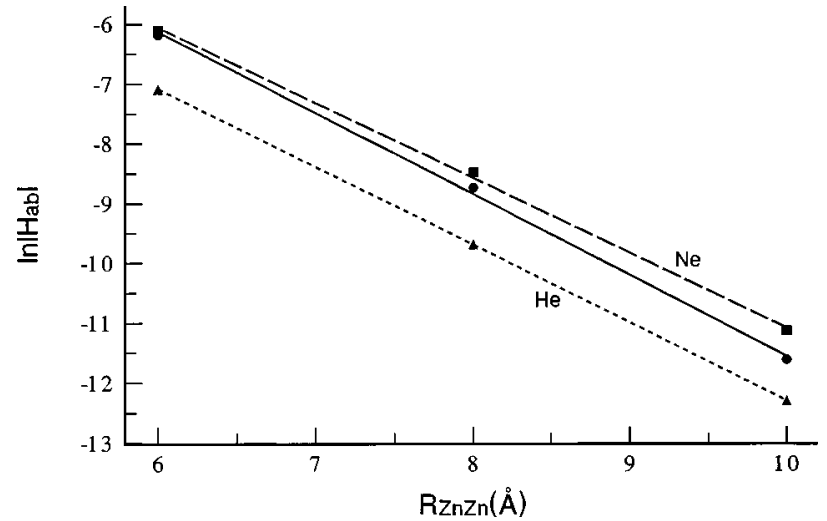

FIG. 1. Plot of $\ln \left|H_{a b}\right|$ for $4 s-4 s$ transfer vs $R_{\mathrm{ZnZn}}$ for $\mathrm{Zn}_{2}^{+}$(solid line, circles), $[\mathrm{Zn}-\mathrm{He}-\mathrm{Zn}]^{+}$(short dashed line, triangles), and $[\mathrm{Zn}-\mathrm{Ne}-\mathrm{Zn}]^{+}$ (long-dashed line, squares). $\mathrm{He}$ or $\mathrm{Ne}$ are placed equidistant from the two $\mathrm{Zn}$. Basis sets and wave functions as defined in Table I.

For example, an et process involving ground-state $\mathrm{Li}$ and $\mathrm{Li}^{+}$exchanging an electron would be denoted $2 s-2 s$ transfer in this shorthand. However, the results are nevertheless based on many-electron wave functions for the initial and final states, not merely one-electron wave functions.

The distance dependence of the electronic coupling was characterized by fitting an exponential to the data, i.e.,

$$
H_{a b}=A \exp (-\beta R / 2),
$$

where $R$ is the internuclear separation between the donor and acceptor, and $\beta$ is the decay constant characterizing the distance dependence of $\left|H_{a b}\right|^{2}$. In almost all cases the exponential represented the data quite well, with correlation coefficients greater than 0.99 .

\section{RESULTS}

\section{A. $\mathrm{M}_{2}^{+}$with a single intervening solvent atom}

In Fig. $1 H_{a b}$ data are presented for $4 s$ to $4 s$ transfer in $\mathrm{Zn}_{2}^{+}$with a single intervening solvent atom ( $\mathrm{He}$ or $\mathrm{Ne}$ ) as a function of $R_{\mathrm{ZnZn}}$. The solvent atom is located at the midpoint of the $\mathrm{Zn}-\mathrm{Zn}$ line of centers. For comparison purposes data are also presented for the corresponding $4 s-4 s$ transfer for $\mathrm{Zn}_{2}^{+}$. (Note, the results with no solvent present are slightly different from $\mathrm{Zn}_{2}^{+}$results presented previously ${ }^{37,38}$ due to differences in the number of states examined and the SA/CASSCF employed. The present results are generally within $10 \%$ of those reported previously.) A single $\mathrm{He}$ at the midpoint of $R_{\mathrm{ZnZn}}$ significantly decreases $H_{a b}$ relative to that obtained with no intervening He. Neon has a small effect on the magnitude of the $\mathrm{Zn}-\mathrm{Zn} H_{a b}$. The decay of $H_{a b}$ with $R_{\mathrm{ZnZn}}$ (see $\beta$ values in Table I) is largely unaffected by the presence or absence of the single He or Ne. This is not unreasonable since $\mathrm{Zn}$ has the lowest ionization potential in these systems, and as such the decay of the $\mathrm{Zn} 4 s$ orbital is expected to be the dominant factor controlling the distance dependence of $H_{a b}$ on $R_{\mathrm{ZnZn}}$ when a fixed number of solvent species is considered. The similar values for $\beta$ reflect the fact that all three cases involve $\mathrm{Zn}-\mathrm{Zn} 4 s-4$ s et.

Analogous results are presented in Fig. 2 for $\mathrm{Li}_{2}^{+}$. Ground-state et $(2 s-2 s)$ is examined and it is again found
TABLE I. Distance dependence data ${ }^{\mathrm{a}}$ for $H_{a b}$.

\begin{tabular}{lcccc}
\hline \hline \multicolumn{1}{c}{ System } & $\Delta R_{\mathrm{MM}}(\AA)$ & Orientation & $\beta\left(\AA^{-1}\right)$ & $A$ (a.u. $)$ \\
\hline $\mathrm{Zn}_{2}^{+}$ & $6-10$ & & 2.71 & 7.5 \\
{$[\mathrm{Zn}-\mathrm{He}-\mathrm{Zn}]^{+}$} & $6-10$ & & 2.61 & 2.1 \\
{$[\mathrm{Zn}-\mathrm{Ne}-\mathrm{Zn}]^{+}$} & $6-10$ & & 2.52 & 4.4 \\
{$[\mathrm{Zn}-\mathrm{Li}-\mathrm{Zn}]^{+}$} & $6-10$ & & 1.08 & 0.26 \\
$\mathrm{Li}_{2}^{+}$ & $6-12$ & & 1.83 & 2.7 \\
{$[\mathrm{Li}-\mathrm{He}-\mathrm{Li}]^{+}$} & $6-12$ & & 1.52 & 0.14 \\
{$[\mathrm{Li}-\mathrm{Ne}-\mathrm{Li}]^{+}$} & $6-12$ & & 1.71 & 1.2 \\
{$\left[\mathrm{Zn}-\mathrm{H}_{2} \mathrm{O}-\mathrm{Zn}\right]^{+}$} & $6-10^{\mathrm{c}}$ & $C_{2 v}$ & 2.09 & 2.2 \\
{$\left[\mathrm{Zn}-\mathrm{H}_{2} \mathrm{O}-\mathrm{Zn}\right]^{+}$} & $6-10^{\mathrm{d}}$ & $C_{2 v}$ & 2.33 & 6.7 \\
{$\left[\mathrm{Zn}-\mathrm{H}_{2} \mathrm{O}-\mathrm{Zn}\right]^{+}$} & $6-10^{\mathrm{e}}$ & perp & 2.39 & 7.4 \\
{$\left[\mathrm{Zn}-\mathrm{H}_{2} \mathrm{O}-\mathrm{Zn}\right]^{+}$} & $6-10^{\mathrm{f}}$ & $\mathrm{OH}$ & 2.53 & 14.5 \\
{$\left[\mathrm{Zn}-\mathrm{H}_{2} \mathrm{O}-\mathrm{Zn}\right]^{+}$} & $6-10^{\mathrm{g}}$ & $\mathrm{HH}$ & 2.49 & 12.5 \\
{$\left[\mathrm{Li}-\mathrm{H}_{2} \mathrm{O}-\mathrm{Li}\right]^{+}$} & $6-12$ & $C_{2 v}$ & 1.66 & 1.8 \\
{$\left[\mathrm{Zn}-\mathrm{NH}_{3}-\mathrm{Zn}\right]^{+}$} & $6-10$ & $\mathrm{~N}$ & 2.32 & 8.5 \\
{$\left[\mathrm{Zn}-\mathrm{NH}_{3}-\mathrm{Zn}\right]^{+}$} & $6-10$ & $\mathrm{H}$ & 2.32 & 8.5 \\
{$\left[\mathrm{Zn}-\mathrm{NH}_{3}-\mathrm{Zn}\right]^{+}$} & $6-10$ & $\mathrm{NH}$ & 2.30 & 9.2 \\
\hline \hline
\end{tabular}

${ }^{a}$ Unless otherwise noted the solvent is at the midpoint of the $\mathrm{M}-\mathrm{M}$ distance. The basis sets used were $\mathrm{Zn}: a$, Li:ANO $(5 s, 3 p, 2 d)$, He: ANO $(5 s, 2 p)$, $\mathrm{Ne}$ : ANO $(6 s, 4 p, 2 d), \mathrm{H}_{2} \mathrm{O}, \mathrm{NH}_{3}: \mathrm{AN}(4 s 2 p / 2 s)$. The wave functions used are $3 / 2$ 2SA/CASSCF for $\mathrm{Zn}_{2}^{+}$(with and without solvent) and 1/2 2SA/CASSCF for $\mathrm{Li}_{2}^{+}$(with and without solvent). Orientation refers to the relative orientation of any molecular solvent used. Further details and definitions of labels are given in the text. Least-squares parameters $(\beta$ and $A)$ from fit to Eq. (2).

${ }^{\mathrm{b}}$ Range of $\mathrm{M}-\mathrm{M}$ distances over which the fit parameters were obtained. ${ }^{\mathrm{c}} \mathrm{O}$ atom $4.0 \AA$ from one $\mathrm{Zn}, \mathrm{H}$ atoms directed at opposite $\mathrm{Zn}$.

${ }^{\mathrm{d}} \mathrm{O}$ atom $3.0 \AA$ from one $\mathrm{Zn}, \mathrm{H}$ atoms directed at opposite $\mathrm{Zn}$.

${ }^{\mathrm{e}} \mathrm{O}$ atom $3.0 \AA$ from one $\mathrm{Zn}$.

${ }^{\mathrm{f}} \mathrm{O}$ atom $3.0 \AA$ from one $\mathrm{Zn}, \mathrm{H}$ along line of centers $2.043 \AA$ from this $\mathrm{Zn}$. ${ }^{g} \mathrm{H}$ atoms on line of centers, projected $\mathrm{O}$ distance along line-of-centers is 3.0 A.

that He diminishes the magnitude of the coupling dramatically, while $\mathrm{Ne}$ has little effect on the electronic coupling. The $\beta$ value for $\mathrm{Li}_{2}^{+}$(Table $\mathrm{I}$ ) is considerably smaller than that for $\mathrm{Zn}_{2}^{+}$since $\beta$ goes roughly as the square root of the IP of the transferring electron ${ }^{39}$ for systems of the type $\mathrm{M}_{2}^{+}$(the ionization potential of $\mathrm{Li}$ at the restricted open HartreeFock/restricted Hartree-Fock ROHF/RHF) level in the basis set used here is $5.3 \mathrm{eV}$, while that for $\mathrm{Zn}$ is $7.7 \mathrm{eV}$ ). With intervening solvent there is not expected to be a direct relationship between $\beta$ and IP, but one might expect differences

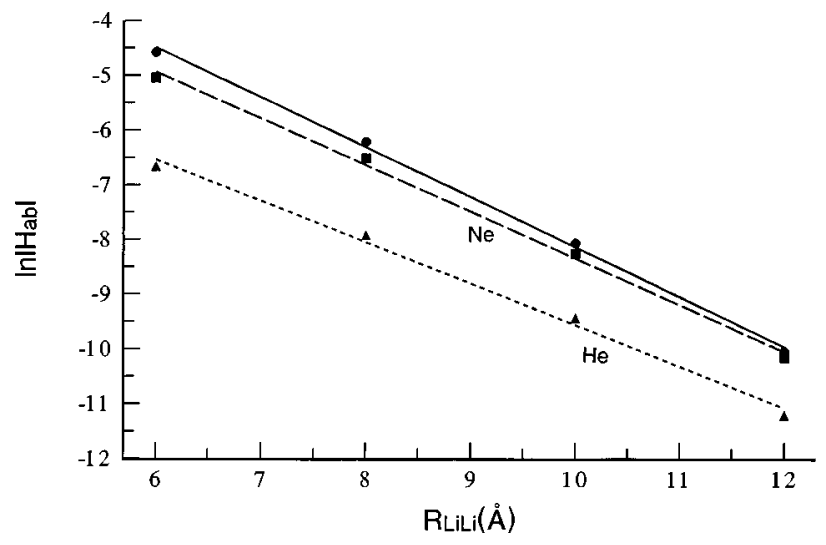

FIG. 2. Plot of $\ln \left|H_{a b}\right|$ for $2 s-2 s$ transfer vs $R_{\mathrm{LiLi}}$ for $\mathrm{Li}_{2}^{+}$(solid line, circles), $[\mathrm{Li}-\mathrm{He}-\mathrm{Li}]^{+}$(short-dashed line, triangles), and $[\mathrm{Li}-\mathrm{Ne}-\mathrm{Li}]^{+}$(long-dashed line, squares). He or $\mathrm{Ne}$ are placed equidistant from the two Li. Basis sets and wave functions as defined in Table I. 


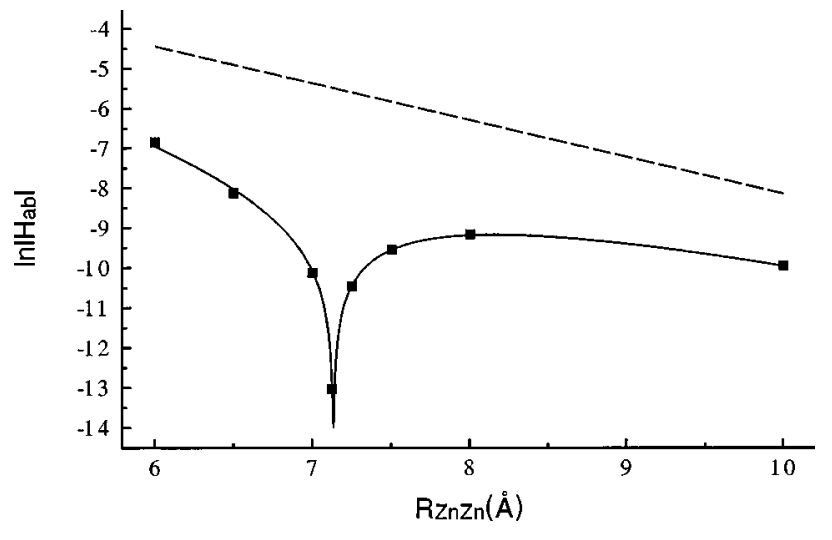

FIG. 3. Plot of $\ln \left|H_{a b}\right|$ vs $R_{\mathrm{ZnZn}}$ for $4 s-4 p$ transfer for $\mathrm{Zn}_{2}^{+}$and $[\mathrm{Zn}-\mathrm{He}-\mathrm{Zn}]^{+}$, the latter with He equidistant from the two $\mathrm{Zn}$. The longdashed line is a linear fit to $\ln \left|H_{a b}\right|$ for $\mathrm{Zn}_{2}^{+}$. The solid line (squares) is for $[\mathrm{Zn}-\mathrm{He}-\mathrm{Zn}]^{+}$, and is based on a fit of the functional form $H_{a b}=A(R$ $\left.-R_{0}\right) \exp (-\beta R / 2)$ (see Ref. 32) to $H_{a b}$ vs distance (note, $\ln \left|H_{a b}\right|$ is plotted). The values of $R_{0}$ and $\beta$ based on the fit are 7.13 and $1.97 \AA^{-1}$, respectively. See text for basis sets and wave functions.

based on the relative energies of the $D / A$ states and the occupied and virtual orbitals of the solvent. Over the range of distances considered, He has a noticeable effect on $\beta$ between the two Li atoms, leading to a lowering by $0.3 \AA^{-1}$.

Both $\mathrm{He}$ and $\mathrm{Ne}$ are atomic solvents with significantly higher ionization potentials than the $D / A$ states of interest. In order to examine the effects of more easily ionized intervening species the system $[\mathrm{Zn}-\mathrm{Li}-\mathrm{Zn}]^{+}$was examined with $\mathrm{Li}$ placed at the midpoint of the $\mathrm{Zn}-\mathrm{Zn}$ distance as $R_{\mathrm{ZnZn}}$ was varied. Four-electron/three-orbital 3SA-CASSCF calculations (using $\mathrm{Zn}$ basis $b$ ) were carried out (the active CASSCF orbitals correspond to the two $\mathrm{Zn} 4 s$ orbitals and the Li $2 s$ orbitals; the three states correspond asymptotically to $\left[\mathrm{Zn}-\mathrm{Li}^{+}-\mathrm{Zn}\right],\left[\mathrm{Zn}-\mathrm{Li}-\mathrm{Zn}^{+}\right]$, and $\left.\left[\mathrm{Zn}^{+}-\mathrm{Li}-\mathrm{Zn}\right]\right)$ followed by a two-state $\mathrm{GMH}$ analysis using the pair of adiabatic states corresponding to $\left[\mathrm{Zn}-\mathrm{Li}-\mathrm{Zn}^{+}\right]$and $\left[\mathrm{Zn}^{+}-\mathrm{Li}-\mathrm{Zn}\right]$. $H_{a b}$ decayed exponentially over the range of 6-10 $\AA$ for $R_{\mathrm{ZnZn}}$ (see Table I) with a significantly smaller value for $\beta$ than for $\mathrm{He}, \mathrm{Ne}$, or no solvent present.

In Fig. $3 \mathrm{GMH}$ results are presented for excited-state $e t$ based on 3/8 4SA/CASSCF calculations (using Zn basis $b$ ) for $[\mathrm{Zn}-\mathrm{He}-\mathrm{Zn}]^{+}$, with $\mathrm{He}$ again at the midpoint of $R_{\mathrm{ZnZn}}$. $H_{a b}$ vs distance is shown for $4 s-4 p$ transfer (with and without He present), arising from the coupling of Valence-Bond states of the form ${ }^{3} P(\mathrm{Zn})-{ }^{2} S\left(\mathrm{Zn}^{+}\right)$and ${ }^{2} S\left(\mathrm{Zn}^{+}\right)-{ }^{1} S(\mathrm{Zn})$. These states are not degenerate at large $R_{\mathrm{ZnZn}}$ and the coupling element is that appropriate to photoinitiated et. Alternatively, $H_{a b}$ so obtained can be viewed as that for thermal et involving the above two VB-type states at a geometry far from the crossing point of their respective diabatic potential surfaces. Previous results ${ }^{37}$ and results reported below indicate that the electronic coupling is not a strong function of the energy separation of the two electronic states involved in the transfer, (i.e., the Condon approximation ${ }^{15,35}$ is valid).

Without intervening He the decay with distance of $H_{a b}$ for $4 s-4 p$ transfer is essentially exponential with distance, with a $\beta$ value $\left(1.85 \AA^{-1}\right)$ somewhat smaller than that for ground-state et, consistent with the slower decay (lower IP)

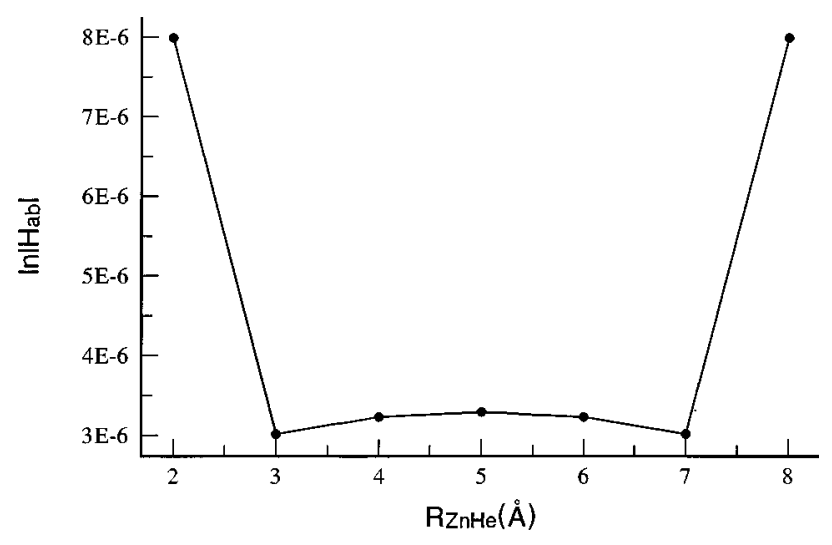

FIG. 4. Plot of $\ln \left|H_{a b}\right|$ vs $R_{\mathrm{ZnHe}}$ for $[\mathrm{Zn}-\mathrm{He}-\mathrm{Zn}]^{+}$with $R_{\mathrm{ZnZn}}=10 \AA$ A. See text for basis sets and wave functions.

of the $\mathrm{Zn} 4 p$ orbital in the ${ }^{3} P$ state. With He present midway between the two $\mathrm{Zn}$ atoms, dramatically different behavior is obtained. The distance dependence of $\ln \left|H_{a b}\right|$ is no longer monotonic; $H_{a b}$ in fact goes through zero near $7 \AA$, changes sign and then increases in magnitude again at shorter $R_{\mathrm{ZnZn}}$. This behavior appears to be due to interference between "direct" and superexchange pathways as will be discussed in the following section. Similar behavior has been observed for coupling through cyclohexane bridges by Braga and Larsson. ${ }^{32}$

The data in Figs. 1-3 address the dependence of the coupling on $R_{\mathrm{ZnZn}}$, and only indirectly address solvent-Zn distance effects ( $v i a$ the change in $R_{\mathrm{ZnZn}}$ ). In Fig. 4 results are presented for $4 s-4 s$ transfer in $[\mathrm{Zn}-\mathrm{He}-\mathrm{Zn}]^{+}$where $R_{\mathrm{ZnZn}}$ is fixed but the position of He along the line-of-centers is varied (3/8 4SA/CASSCF calculations, $\mathrm{Zn}$ basis set $b$ ). To the extent that the Condon approximation is valid one would expect $H_{a b}$ to remain constant as $R_{\mathrm{ZnHe}}$ varies, since $R_{\mathrm{ZnZn}}$ is fixed at $10 \AA$. Note that in Fig. 4 both the ordinate and abscissa are linear scales. It is seen that there is some variation in the coupling as He is moved away from the midpoint of $R_{\mathrm{ZnZn}}$, closer to one of the $\mathrm{Zn}$. At $R_{\mathrm{ZnHe}}=2.0 \AA$ one of the $\mathrm{Zn}$ and $\mathrm{He}$ begin to interact significantly and $H_{a b}$ increases by a factor of 2.6. However, where $\mathrm{He}$ and $\mathrm{Zn}$ interact weakly the position dependence is quite modest. Similar weak position dependence of the coupling element when $D / A$ and solvent are weakly interacting is observed below for molecular solvent species.

Results were also obtained for $\left[\mathrm{Zn}-\mathrm{H}_{2} \mathrm{O}-\mathrm{Zn}\right]^{+}$as a function of: (a) $R_{\mathrm{ZnZn}}$ with $R_{\mathrm{ZnO}}$ fixed [Fig. 5(a)] $R_{\mathrm{ZnO}}$ with $R_{\text {ZnZn }}$ fixed [Fig. 5(b)]. Four different orientations were considered for the intervening water molecule: (a) O located on the $\mathrm{Zn}-\mathrm{Zn}$ line of centers, with the water molecular plane perpendicular to the $\mathrm{Zn}-\mathrm{Zn}$ axis ("perpendicular" orientation), (b) both $\mathrm{H}$ atoms located on the $\mathrm{Zn}-\mathrm{Zn}$ line of centers, water $C_{2 v}$ axis perpendicular to the $\mathrm{Zn}-\mathrm{Zn}$ axis (" $\mathrm{HH}$ " orientation), (c) $\mathrm{O}$ located on the $\mathrm{Zn}-\mathrm{Zn}$ line of centers, water $C_{2 v}$ axis along the $\mathrm{Zn}-\mathrm{Zn}$ axis (" $C_{2 v}$ " orientation), and (d) an $\mathrm{O}-\mathrm{H}$ bond located on the $\mathrm{Zn}-\mathrm{Zn}$ line of centers (" $\mathrm{OH}$ ", orientation).

In Table I results for $H_{a b}$ vs $R_{\mathrm{ZnZn}}$ for $\mathrm{Zn}_{2}^{+} 4 s-4 s$ transfer are presented for all four water orientations, and in Fig. 

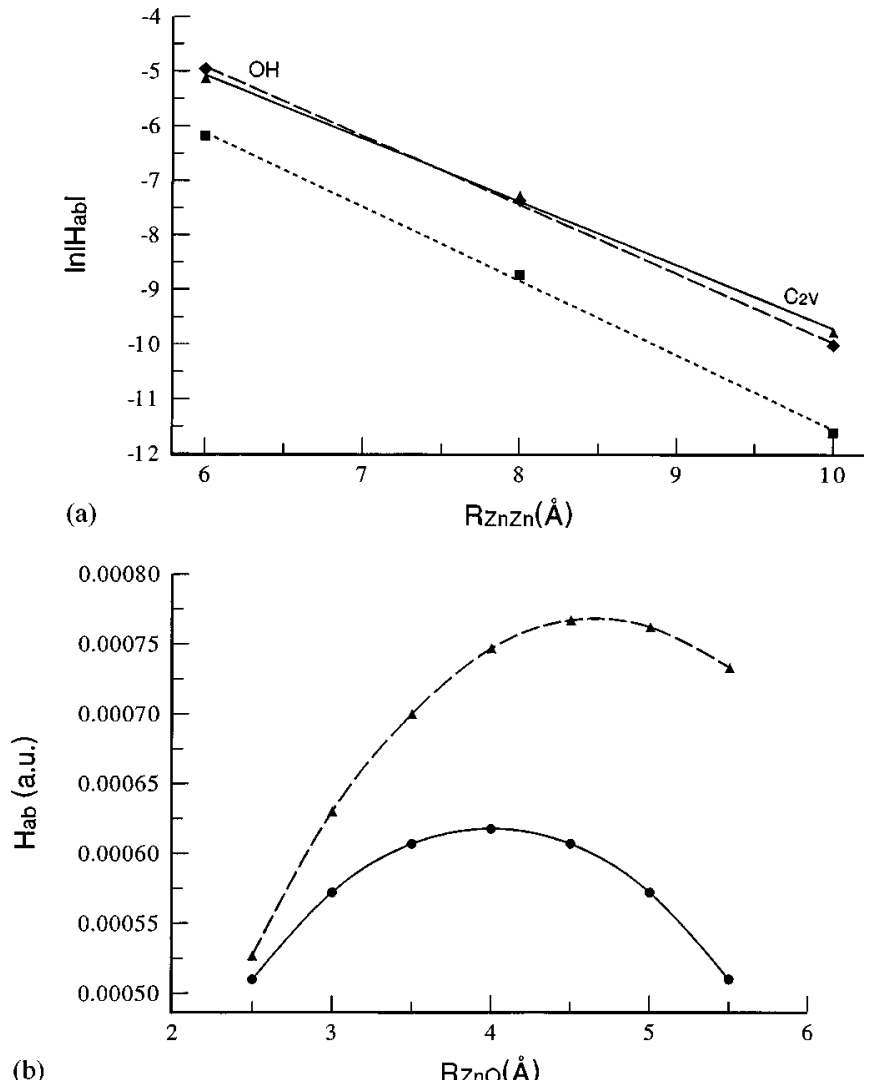

(b)

FIG. 5. (a) Plot of $\ln \left|H_{a b}\right|$ for $4 s-4 s$ transfer vs $R_{\mathrm{ZnZn}}$ for $\mathrm{Zn}_{2}^{+}$(dashed line, squares), and $\left[\mathrm{Zn}-\mathrm{OH}_{2}-\mathrm{Zn}\right]^{+}$with water in either the $C_{2 v}$ orientation (solid line, triangles), or the $\mathrm{OH}$ orientation (long-dashed line, diamonds). In either of the latter two cases the oxygen is placed $3 \AA$ from one $\mathrm{Zn}$. In the $C_{2 v}$ orientation the $\mathrm{H}$ atoms are directed at the other $\mathrm{Zn}$, in the $\mathrm{OH}$ orientation the $\mathrm{H}$ atom along the line of centers is directed at the $\mathrm{Zn}$ atom which is $3 \AA$ from the $\mathrm{O}$ atom. Basis sets and wave functions as defined in Table I. (b) $H_{a b}$ for $4 s-4 s$ transfer vs $R_{\mathrm{ZnO}}$ for $\left[\mathrm{Zn}-\mathrm{OH}_{2}-\mathrm{Zn}\right]^{+}$with $R_{\mathrm{ZnZn}}=8 \AA$. The solid line (circles) is for water in the perp orientation, the dashed line (triangles) is for the $\mathrm{OH}$ orientation (with $R_{\mathrm{ZnH}}$ for the $\mathrm{H}$ on the line of centers less than $R_{\mathrm{ZnO}}$ ). Basis sets and wave functions as defined in Table I.

5(a) data are shown for the $\mathrm{OH}$ and $C_{2 v}$ orientations, $(\mathrm{O}$ atom coordinate along the $\mathrm{Zn}-\mathrm{Zn}$ line of centers is $3 \AA$ from one of the $\mathrm{Zn}$ ). The results for the other orientations are similar to those presented in Fig. 5(a). For comparison purposes, $H_{a b}$ for $\mathrm{Zn}_{2}^{+}$(no solvent present) is also presented. It is seen that the presence of water between the two $\mathrm{Zn}$ atoms leads to a significant increase in $H_{a b}$ at all $R_{\mathrm{ZnZn}}$, but there is at best a modest variation in $H_{a b}$ with water orientation. The $\beta$ values are somewhat smaller than those with no water present (Table I).

The results in Fig. 5(b) show the dependence of $H_{a b}$ for $\mathrm{Zn}_{2}^{+} 4 s-4 s$ transfer as a function of water position for fixed $R_{\mathrm{ZnZn}}(=8 \AA)$. The variation is at most $50 \%$ over the range of water positions, again lending qualitative support to the Condon approximation.

Calculations were also performed for $\left[\mathrm{Li}-\mathrm{H}_{2} \mathrm{O}-\mathrm{Li}\right]^{+}$ with water in the $C_{2 v}$ geometry described above and the results from the fit to Eq. (2) are presented in Table I. For $\mathrm{Li}_{2}^{+}$the presence of intervening water has a much smaller effect on $H_{a b}$ than for the $\mathrm{Zn}_{2}^{+}$system. At short $R_{\mathrm{LiLi}}$ there is essentially no effect, while at the largest $R_{\mathrm{LiLi}}$ considered

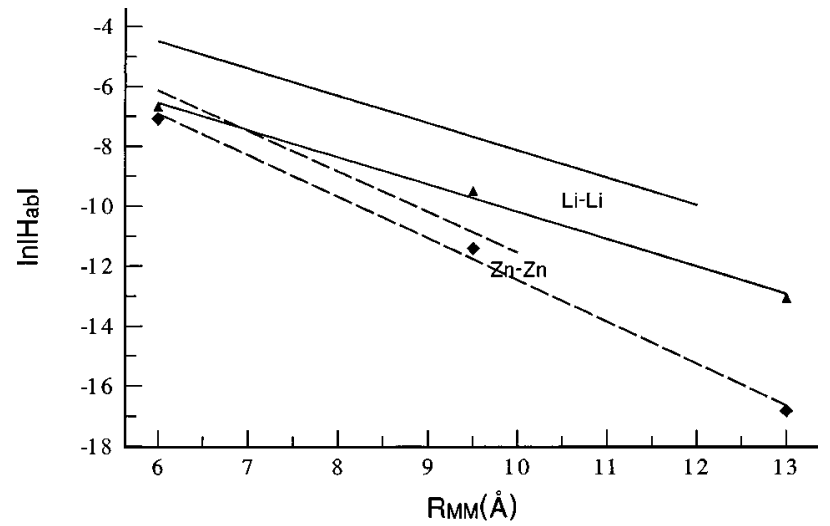

FIG. 6. Plot of $\ln \left|H_{a b}\right|$ for $4 s-4 s$ transfer vs $R_{\mathrm{MM}}(\mathrm{M}=\mathrm{Li}$ or $\mathrm{Zn})$ for $\left[\mathrm{M}-(\mathrm{He})_{n}-\mathrm{M}\right]^{+}(n=1-3)$. For comparison purposes $\ln \left|H_{a b}\right|$ for $s-s$ transfer vs $R_{\mathrm{MM}}(\mathrm{M}=\mathrm{Li}$ or $\mathrm{Zn})$ for $[\mathrm{M}-\mathrm{M}]^{+}$is also plotted. Solid lines are for $\mathrm{M}=\mathrm{Li}$. upper line: No He present, lower line: With He present (triangles). Long-dashed lines are for $\mathrm{M}=\mathrm{Zn}$, upper line: No He present, lower line: With He present(diamonds). Basis sets and wave functions as defined in Table I.

$H_{a b}$ is increased by at most a factor of 2 . In addition, little to no effect is seen on $\beta$.

Ammonia was also considered as a solvent and values for $\beta$ are presented in Table I for $\left[\mathrm{Zn}-\mathrm{NH}_{3}-\mathrm{Zn}\right]^{+}$for several $\mathrm{NH}_{3}$ orientations. The orientations include: (a) $\mathrm{N}$ located on the $\mathrm{Zn}-\mathrm{Zn}$ line of centers, ammonia $C_{3 v}$ axis perpendicular to the $\mathrm{Zn}-\mathrm{Zn}$ axis, (" $\mathrm{N}$ ' orientation), (b) $\mathrm{N}$ located off the $\mathrm{Zn}-\mathrm{Zn}$ line of centers, with the $\mathrm{Zn}-\mathrm{Zn}$ axis contained in the plane formed by the ammonia $\mathrm{H}$ atoms (" $\mathrm{H}$ '" orientation), (c) one $\mathrm{N}-\mathrm{H}$ bond along the $\mathrm{Zn}-\mathrm{Zn}$ line of centers. In all cases the $\mathrm{N}$ atom is located symmetrically with respect to the $\mathrm{Zn}$ atoms. As was the case with water, we find that the presence of an intervening ammonia molecule significantly increases $H_{a b}$ at a given $R_{\mathrm{ZnZn}}$, but there is little variation in $H_{a b}$ with ammonia orientation. We also find that for fixed $R_{\mathrm{ZnZn}}$, as the position of the ammonia between the $\mathrm{Zn}$ atoms is varied, $H_{a b}$ varied by at most $30 \%$ over a $\pm 3 \AA$ range ( 'N' orientation, $R_{\mathrm{ZnZn}}=10 \AA$ ).

\section{B. $\mathrm{M}_{2}^{+}$with multiple intervening solvent atoms-molecules}

Compared to the single solvent molecule case, $H_{a b}$ can have a quite different distance dependence when the $\mathrm{M}-\mathrm{M}$ distance is increased with an increasing number of intervening atoms-molecules, due to superexchange interactions. The effects of intervening methanes or waters in idealized geometries have been studied previously. ${ }^{15}$ In this section results are presented for multiple $\mathrm{He}$ atoms or water molecules, using either $\mathrm{Zn}_{2}^{+}$or $\mathrm{Li}_{2}^{+}$as the $D / A$ pair.

In Fig. $6 \ln \left|H_{a b}\right|$ vs distance is presented for $\mathrm{Zn}_{2}^{+}$and $\mathrm{Li}_{2}^{+}$ with successive He placed along the line of centers. We assume a radius for each $\mathrm{He}$ of $1.75 \AA$ (based on the radial distribution function for liquid $\mathrm{He}$ at between 1.5 and $4.2{ }^{\circ} \mathrm{K}^{54}$ ). The data points represent insertion of successive He accompanying increased $\mathrm{M}-\mathrm{M}$ distances of $3.5 \AA$, with the initial $\mathrm{M}-\mathrm{M}$ distance of $6 \AA$ (one He present). In each case the coupling is smaller than with no He present, and the decay with distance is essentially that for $\mathrm{M}_{2}^{+}$. The distance 


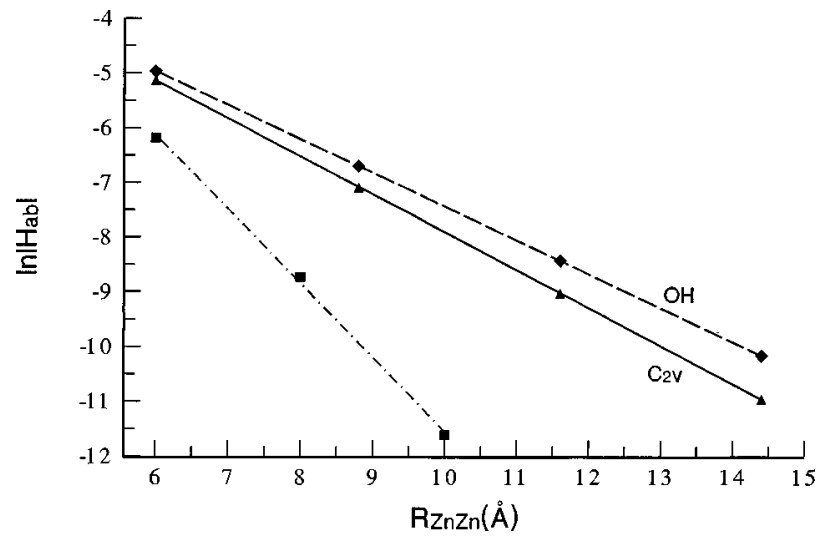

FIG. 7. Plot of $\ln \left|H_{a b}\right|$ for $4 s-4 s$ transfer vs $R_{\mathrm{ZnZn}}$ for $\mathrm{Zn}_{2}^{+}$(dash-dot line, squares), and $\left[\mathrm{Zn}-\left(\mathrm{OH}_{2}\right)_{n}-\mathrm{Zn}\right]^{+}(n=1-4)$ with water in either the $C_{2 v}$ orientation (solid line, triangles), or the $\mathrm{OH}$ orientation (long-dashed line, diamonds). The assumed water diameter is $2.8 \AA$. Basis sets and wave functions as defined in Table I.

dependence is not strictly exponential, and this behavior likely arises due to an even-odd alternation with increasing $\mathrm{He}$, much as one observes for alternant hydrocarbons. ${ }^{15}$

In order to examine superexchange effects with a molecular solvent, calculations analogous to those in Fig. 6 were performed using water as the solvent (Fig. 7). As in the single water case, several geometries were investigated. The water diameter chosen for the calculations in Fig. 7 was 2.8 $\AA$, but results are presented in Table II for water diameters of 2.8 and $3.0 \AA$. The $2.8 \AA$ value is twice the van der Waals radius of $\mathrm{O},{ }^{55}$ the latter value allows one to assess how small variations in $\mathrm{O}-\mathrm{O}$ distance (perhaps due to local density fluctuations) might alter $H_{a b}$ and its distance dependence. The three orientations examined for the waters were the perpendicular, $C_{2 v}$, and $\mathrm{OH}$ orientations used in the single water calculations. For each orientation, as successive waters

TABLE II. Distance dependence data ${ }^{\mathrm{a}}$ for $H_{a b}$; multiple solvent.

\begin{tabular}{lccccc}
\hline \hline \multicolumn{1}{c}{ System } & $\begin{array}{c}\Delta R_{\mathrm{ZnZn}} \\
(\AA)^{\mathrm{b}}\end{array}$ & $\begin{array}{c}\Delta r_{\text {solvent }} \\
(\AA)^{\mathrm{c}}\end{array}$ & $n^{\mathrm{d}}$ & $\beta\left(\AA^{-1}\right)^{\mathrm{e}}$ & $A^{\mathrm{e}}($ a.u. $)$ \\
\hline$\left[\mathrm{Zn}-\mathrm{He}_{n}-\mathrm{Zn}\right]^{+}$ & $6.0-16.5$ & 3.5 & $1-4$ & 2.78 & 4.3 \\
{$\left[\mathrm{Li}-\mathrm{He}_{n}-\mathrm{Li}\right]^{+}$} & $6.0-16.5$ & 3.5 & 1 to 2 & 1.83 & 0.35 \\
{$\left[\mathrm{Zn}-\left(\mathrm{H}_{2} \mathrm{O}\right)_{n}-\mathrm{Zn}\right]^{+}$} & $8.0-16.4$ & 2.8 & $C_{2 v}, 1-4$ & 1.38 & 0.16 \\
{$\left[\mathrm{Zn}-\left(\mathrm{H}_{2} \mathrm{O}\right)_{n}-\mathrm{Zn}\right]^{+}$} & $8.0-16.4$ & 2.8 & $\mathrm{OH}, 1-4$ & 1.25 & 0.11 \\
{$\left[\mathrm{Zn}-\left(\mathrm{H}_{2} \mathrm{O}\right)_{n}-\mathrm{Zn}\right]^{+}$} & $8.0-16.4$ & 2.8 & perp, 1-4 & 1.36 & 0.14 \\
{$\left[\mathrm{Zn}-\left(\mathrm{H}_{2} \mathrm{O}\right)_{n}-\mathrm{Zn}\right]^{+}$} & $6.0-14.4$ & 2.8 & $C_{2 v}, 1-4$ & 1.39 & 0.38 \\
{$\left[\mathrm{Zn}-\left(\mathrm{H}_{2} \mathrm{O}\right)_{n}-\mathrm{Zn}\right]^{+}$} & $6.0-14.4$ & 2.8 & $\mathrm{OH}, 1-4$ & 1.24 & 0.29 \\
{$\left[\mathrm{Zn}-\left(\mathrm{H}_{2} \mathrm{O}\right)_{n}-\mathrm{Zn}\right]^{+}$} & $6.0-14.4$ & 2.8 & perp, 1-4 & 1.39 & 0.34 \\
{$\left[\mathrm{Zn}-\left(\mathrm{H}_{2} \mathrm{O}\right)_{n}-\mathrm{Zn}\right]^{+}$} & $8.0-17.0$ & 3.0 & $C_{2 v}, 1-4$ & 1.46 & 0.22 \\
{$\left[\mathrm{Zn}-\left(\mathrm{H}_{2} \mathrm{O}\right)_{n}-\mathrm{Zn}\right]^{+}$} & $8.0-17.0$ & 3.0 & $\mathrm{OH}, 1-4$ & 1.34 & 0.16 \\
{$\left[\mathrm{Li}-\left(\mathrm{H}_{2} \mathrm{O}\right)_{n}-\mathrm{Li}\right]^{+}$} & $8.0-16.4$ & 2.8 & $C_{2 v}, 1-4$ & 1.34 & 0.56 \\
{$\left[\mathrm{Li}-\left(\mathrm{H}_{2} \mathrm{O}\right)_{n}-\mathrm{Li}\right]^{+}$} & $8.0-16.4$ & 2.8 & $\mathrm{OH}, 1-3$ & 1.27 & 0.48 \\
\hline \hline
\end{tabular}

${ }^{\mathrm{a}}$ Basis set and wave function information as given in Table I, footnote a.

${ }^{b}$ Range of $\mathrm{M}-\mathrm{M}$ distances. Initial value is that for $\mathrm{M}-\mathrm{M}$ with one solvent $\left(\mathrm{He}, \mathrm{H}_{2} \mathrm{O}\right)$ present, with $\mathrm{He}$ or $\mathrm{O}$ at the $\mathrm{M}-\mathrm{M}$ midpoint. Increasing distances based on assumed solvent diameter, with addition of extra solvent and translation of one $\mathrm{Zn}$ by the solvent diameter.

${ }^{c}$ Solvent diameter (see text).

${ }^{\mathrm{d}}$ Denotes the orientation and range of number of solvent atoms-molecules used in calculating $\beta$.

${ }^{e}$ Values based on fit to Eq. (2).
TABLE III. Condon approximation test ${ }^{\mathrm{a}}$ using $\left[\mathrm{Zn}_{1}-\left(\mathrm{OH}_{2}\right)_{\text {in }}\right.$ $\left.-\mathrm{Zn}_{r}-\left(\mathrm{OH}_{2}\right)_{\text {out }}\right]^{+}$.

\begin{tabular}{ccc}
\hline \hline$R_{\mathrm{Zn}-\mathrm{Zn}}(\AA)$ & $R_{\text {Znr-(O)out }}(\AA)^{\mathrm{b}}$ & $H_{a b}($ hartrees $)$ \\
\hline 6.0 & $\infty$ & $5.92 e-3$ \\
6.0 & 3.0 & $6.15 e-3$ \\
6.0 & 2.0 & $6.88 e-3$ \\
8.0 & $\infty$ & $6.86 e-4$ \\
8.0 & 3.0 & $7.68 e-4$ \\
8.0 & 2.0 & $9.67 e-4$ \\
10.0 & $\infty$ & $5.66 e-5$ \\
10.0 & 3.0 & $6.81 e-5$ \\
10.0 & 2.0 & $1.00 e-4$ \\
\hline \hline
\end{tabular}

${ }^{\mathrm{a}}$ Basis sets and wave functions as described in Table I, footnote a. $R_{\mathrm{Zn} 1-(\mathrm{O}) \text { in }}=3.0 \AA$.

${ }^{\mathrm{b}}$ Denotes distance between right-most $\mathrm{Zn}$ and outer water $\mathrm{O}$

were added, they assumed the same orientation as the preceding water, hence in the multiple perpendicular water results all $\mathrm{H}_{2} \mathrm{O}$ have the perpendicular geometry. Up to four intervening waters were considered, beginning from initial (one water present) $R_{\mathrm{ZnZn}}$ of either 6 or $8 \AA$. The multiple intervening waters not only significantly increase the electronic coupling at a given $R_{\mathrm{ZnZn}}$ but the rate of decay is significantly diminished (see Table II for $\beta$ values), irrespective of the water orientation considered. It is seen that use of a larger average radius for water leads to a modest increase in $\beta$, as one might expect based on a McConnell-type model. ${ }^{22}$ In test calculations with an average water radius of nearly $3.9 \AA$, the $\beta$ value for all water orientations increases to $\sim 1.7 \AA^{-1}$ and is essentially orientation independent. The above results show that for smaller radii, variations in $\beta$ and the magnitude of $H_{a b}$ are observed as the water orientation changes, but they are modest compared to the differences in $H_{a b}$ and $\beta$ that arise relative to no waters present.

Similar multiwater calculations were also performed for $\mathrm{Li}_{2}^{+}$, only treating the $C_{2 v}$ and $\mathrm{OH}$ water orientations (see Table II). In this case there is less change in the coupling relative to that obtained with no $\mathrm{H}_{2} \mathrm{O}$ present than with $\mathrm{Zn}$ as $D / A$.

The results presented above addressed non-Condon effects on $H_{a b}$ through the geometry sensitivity of $H_{a b}$ at fixed $R_{\text {ZnZn }}$ [Fig. 5]. The results in Table III examine non-Condon behavior in a somewhat different manner. These calculations treat a complex having the geometry $\left[\mathrm{Zn}_{1}-\mathrm{OH}_{2}\right.$ $\left.-\mathrm{Zn}_{r}-\mathrm{OH}_{2}\right]^{+}$, each water having the $C_{2 v}$ orientation. The $\mathrm{Zn}_{1}-\mathrm{OH}_{2}$ distance was fixed at $3.0 \AA$, the $\mathrm{Zn}_{r}-\mathrm{OH}_{2}$ distance was set at 2.0 or $3.0 \AA$, or the outer water was completely removed ( $\infty$ ) and the $R_{\mathrm{ZnZn}}$ distance was varied from 6.0 to $10.0 \AA$ A . It has been shown previously that the "outer" water has little effect on $H_{a b}$ when no intervening solvent is present, even though the presence of water at 2 (3) $\AA$ lowers the $\mathrm{Zn}$ IP by about 2 (1) eV. ${ }^{37}$ By keeping the $\mathrm{Zn}_{1}-\mathrm{OH}_{2}$ distance fixed and changing the $\mathrm{Zn}_{r}-\mathrm{OH}_{2}$ distance one alters the relative energies of the $D$ and $A$ orbitals, leading to potentially different coupling elements at a given $R_{\mathrm{ZnZn}}$, i.e., possible non-Condon behavior for the through-solvent superexchange coupling. It is seen that at $R_{\mathrm{ZnZn}}=6.0 \AA$ the variation of $H_{a b}$ with $\mathrm{Zn}_{r}-\mathrm{OH}_{2}$ distance is quite small. At $R_{\mathrm{ZnZn}}=10 \AA$ the variation is less than a factor of 2 (compared 
to no outer water present). While the Condon approximation does not rigorously hold, the coupling is not strongly dependent on the outer water position.

\section{DISCUSSION}

It is clear from the data discussed above that the mediation of the electronic coupling by solvent can have widely varying behavior as a function of solvent and donoracceptor properties. To briefly summarize the results, we find that: (i) The two atomic solvents considered ( $\mathrm{He}$ and $\mathrm{Ne}$ ) either diminished $H_{a b}$ or left it largely unchanged (when compared with the same $D-A$ distance and no solvent present), (ii) multiple $\mathrm{He}$ atoms had little effect on the rate of decay of $H_{a b}$, (iii) the molecular solvents considered, $\mathrm{H}_{2} \mathrm{O}$ and $\mathrm{NH}_{3}$, markedly increased $H_{a b}$ and reduced $\beta$ (in the multiple solvent molecule cases), (iv) the effects seen for the molecular solvents were, to a first approximation, independent of the solvent's orientation, and (v) Ne and the molecular solvents produce quite different effects on $H_{a b}$, even though they are isoelectronic. These features are discussed below.

\section{A. Superexchange coupling involving one or more He}

The decrease in the electronic coupling due to an intervening He atom may at first seem surprising. However, for a system involving $s-s$ transfer, with an intervening $s$-type orbital capable of a superexchange interaction with the $D$ and $A$ orbitals, one can show that an interference between direct and superexchange pathways may occur, leading to potentially destructive interference and diminished $H_{a b}$. For example, consider a one-electron model in which $\phi_{D}$ and $\phi_{A}$ are identical $s$-like orbitals having equal zeroth-order energies. For simplicity assume there is a single intervening solvent (symmetrically placed) with an $s$ orbital, $\phi_{S}$, that can undergo superexchange coupling with $D$ and $A$. We also assume $E_{S}<E_{D, A}$, as is the case for $\mathrm{He}$ as solvent, and that the relative signs of $\phi_{D}$ and $\phi_{A}$ are such that $H_{D A}$ is negative. (The sign convention has no effect on the final result; it is assumed here for simplicity.) When $\phi_{D}$ and $\phi_{A}$ interact with $\phi_{S}$, one obtains new zeroth-order states of the form $\phi_{D}^{\prime}=\phi_{D}+\phi_{S} H_{D S} /\left(E_{D}-E_{S}\right)$ and $\phi_{A}^{\prime}=\phi_{A}+\phi_{S} H_{A S} /\left(E_{D}\right.$ $\left.-E_{S}\right)$. Forming $H_{D^{\prime} A^{\prime}}$, taking proper account of nonorthogonality, ${ }^{22}$ one obtains $H_{D^{\prime} A^{\prime}}=H_{D A}+H_{D S} H_{S A} /\left(E_{D}\right.$ $-E_{S}$ ). One can show that the two terms in the expression for $H_{D^{\prime} A^{\prime}}$ are of opposite sign, leading to destructive interference. In most instances where superexchange coupling is important the direct term is expected to be small, but when the coupling to solvent is weak (as is expected for He as solvent) the two terms may be of comparable size, leading to an overall decrease in $H_{a b}$. In addition, since these two terms need not have the same distance dependence, their relative magnitude need not be constant as a function of $D-A$ separation. This behavior is observed in Fig. 3 for $4 s-4 p$ transfer, where $H_{a b}$ for $4 s-4 p$ transfer goes through zero due to the different distance dependence for these two paths.

Using similar arguments for the case of two intervening He one obtains:

$$
\begin{aligned}
H_{D^{\prime} A^{\prime}}= & H_{D A}+H_{D S 1} H_{S 1 A} /\left(E_{D}-E_{S}\right) \\
& +H_{D S r} H_{S r A} /\left(E_{A}-E_{S}\right) \\
& +H_{D S 1} H_{S 1 S r} H_{S r A} /\left[\left(E_{D}-E_{S}\right)\left(E_{A}-E_{S}\right)\right],
\end{aligned}
$$

where $S 1$ and $S r$ denote the two possible intervening solvent atoms. Based on the above assumptions the first and fourth terms have negative signs while the second and third are positive. If the fourth term is larger than terms two and three one would expect $H_{a b}$ for two intervening $\mathrm{He}$ atoms to be larger than that for no intervening He. In fact, with two intervening $\mathrm{He}$ atoms the value of $H_{a b}$ is less than a factor of 2 different from that with no $\mathrm{He}$ present although still smaller. Of course, in order for the fourth term to be large, $H_{S 1 S r}$ needs to be reasonably large, which may not be the case given it involves the coupling element between two $\mathrm{He}$ and the $\mathrm{He}-\mathrm{He}$ separation is fairly large. Our results do not allow us to directly assess the size of $H_{S 1 S r}$, but it is not unreasonable to assume that, given the slower decay of the $D$ and $A$ orbitals, a quantity like $H_{D S r}$ might be large enough (relative to $H_{D S 1} H_{S 1 S r}$ ) for the second and third terms to still be important. In similar work Heifets et al. ${ }^{56}$ found a chain of He could mediate the electronic coupling over a $20 \AA$ distance, but their inter-He spacing was significantly smaller than ours, leading to larger values of $H_{S 1 S r}$, and, one expects, larger contributions from nearest-neighbor hopping.

It should be noted that the destructive interference is predicated on $E_{S}<E_{D, A}$ for $s-s$ transfer; in fact the interference would be constructive were $E_{S}>E_{D, A}$. That we appear to observe destructive interference for the $\mathrm{He}$ case suggests that the primary superexchange coupling route is via hole transfer. Our many-electron calculations do not permit us to apply the elegant analysis of Stuckebruhkov to assess hole and particle contributions to the coupling. ${ }^{30}$ However, we have used a miminum basis set ANO description in a series of test calculations, and found that the results obtained for $[\mathrm{Zn}-\mathrm{He}-\mathrm{Zn}]^{+}$with He symmetrically placed between the $\mathrm{Zn}$ differed by no more than $30 \%$ from those with the large $\mathrm{He}$ basis. This basis affords no virtual orbitals on the He (i.e., no orbitals to promote particle transfer). Given the factor of 2 to 3 difference between $H_{a b}$ with and without He present, these values are in good enough agreement with the large basis results to suggest that the dominant superexchange pathway is via hole transfer.

\section{B. Superexchange interaction with one or more molecular solvent species}

The most striking feature of these results is the large increase observed for $H_{a b}$ with $\mathrm{H}_{2} \mathrm{O}$ or $\mathrm{NH}_{3}$ as solvent. In analogous fashion to the calculations on $\mathrm{He}$, we have performed calculations using minimum basis set (ANO) water to assess the relative importance of hole and particle transfer for water's superexchange coupling. Using water in the perpendicular geometry (where, in the minimum basis set, there would be no $2 p$-like unoccupied orbitals, and fewer $A^{\prime}$ water virtual orbitals), we find no more than a thirty percent difference between the minimum basis set and larger water basis set results, even at up to three intervening waters (water spacing $\sim 3.9 \AA$ ). (At the largest $\mathrm{Zn}-\mathrm{Zn}$ separation, $H_{a b}$ 
would be at least two orders of magnitude smaller, were no waters present.) Since we are unable to remove all unoccupied water orbitals we cannot conclude definitively that the coupling is purely holelike. However, the basis set truncation involved in use of a minimum basis set description for water removes seven of the nine unoccupied orbitals (including the only $\mathrm{O} p$-like virtual orbital, which would be expected to have greatest overlap with $D$ and $A$ orbitals in this geometry), and the change in the coupling is quite modest, strongly suggesting that hole transfer is the dominant mechanism in the water-as-solvent case.

For the Zn-containing systems the orientation of the solvent is found to be of little importance. This last fact is perhaps most surprising, since the orientations chosen would appear to maximize the superexchange interactions with quite different orbitals. Assuming that hole transfer is the dominant mechanism for water, the interaction with the occupied water orbitals is the most relevant factor to consider. For example, in the perpendicular orientation, one might expect largest overlap with an $\mathrm{O} 2 p$-like orbital, whereas in the $C_{2 v}$ orientation the coupling could occur through a lone pair and/or an $A_{1} \mathrm{OH}$ bonding orbital. Nevertheless, the results indicate that all orientations are of similar "value" in promoting the electronic coupling. On the other hand, one might have expected similar behavior for water (or ammonia) and $\mathrm{Ne}$, and they behave quite differently. In a one-electron analysis similar to that used for $\mathrm{He}$ above, the $\mathrm{Ne} 2 s$ and $2 p$ orbitals offer independent superexchange pathways which themselves destructively interfere. The numerical results suggest that this cancellation is essentially complete, leading to a value of $H_{D^{\prime} A^{\prime}}$ that is nearly identical to $H_{D A}$. The lowered symmetry in water or ammonia may be responsible for incomplete cancellation of the various pathways available in the molecular cases, leading to an overall increase in the coupling.

The multiple water calculations show a significant decrease in $\beta$ for $\mathrm{Zn}$ as $D / A$. The value of $\beta$ for $\mathrm{Li}$ as $D / A$ decreases with multiple intervening waters, but to a smaller extent than Zn. Of course, one expects that the size of the superexchange coupling will depend in part on the relative energy of the $D / A$ and solvent, and thus it is reasonable that $\mathrm{Li}$ and $\mathrm{Zn}$ behave differently in this case. Indeed, a single intervening water has a much larger effect on the $\mathrm{Zn}-\mathrm{Zn}$ coupling than the $\mathrm{Li}-\mathrm{Li}$ coupling, suggesting that the longrange effect as multiple water molecules are interposed between the two Li should be smaller.

\section{Condon approximation}

The results presented above lend qualitative support to use of the Condon approximation in these systems. The results for $\mathrm{H}_{a b}$ as a function of: (a) $\mathrm{He}$ or $\mathrm{H}_{2} \mathrm{O}$ placement between the two $\mathrm{Zn}$ at fixed $R_{\mathrm{ZnZn}}$, (b) $\mathrm{H}_{2} \mathrm{O}$ orientation between the two $\mathrm{Zn}$ at fixed $R_{\mathrm{ZnO}}$ and $R_{\mathrm{ZnZn}}$, and (c) outer water position in $\left[\mathrm{Zn}-\mathrm{OH}_{2}-\mathrm{Zn}-\mathrm{OH}_{2}\right]^{+}$show a modest variation with geometry (factor of 2 ), but in all cases this variation is small relative to the dependence of $H_{a b}$ on $D-A$ distance. Clearly there may be some cases where such geometry dependence will be important to consider as, for example, the vibrationally state-resolved et rates studied by
Spears and co-workers. ${ }^{57}$ In these cases it may be that nonCondon behavior (position dependent $H_{a b}$ ) may play a role in determining the relative rates of $e t$ from the various states. However, in most cases one is confronted with thermally and position-averaged data for $H_{a b}$ and the relatively small error introduced by geometric variation appears to be negligible in comparison with other uncertainties in the theoretical analysis of such systems.

\section{Comparison with previous results}

Four previous theoretical studies have addressed the distance and orientation dependence of the electronic coupling element in water. Newton and Cave ${ }^{15}$ examined watermediated coupling between methyl radicals using idealized geometries and also found relatively low values for $\beta$ (1.0 $\AA^{-1}$ ). Larsson ${ }^{20}$ examined the electronic coupling in $\mathrm{Fe}\left(\mathrm{H}_{2} \mathrm{O}\right)^{+2 /+3}$ self-exchange reactions as a function of distance, with waters added between $D$ and $A$ as the $D-A$ distance is increased. He used extended Hückel theory and a 3.0 $\AA$ diam for water and obtained a value for $\beta$ of $\sim 2.4 \AA^{-1}$. $\mathrm{He}$ also found that the direct interaction (complex-tocomplex) was, in most orientations examined, overshadowed by the through-solvent coupling. The larger value for $\beta$ obtained by Larsson may arise from $D / A$ energy differences and/or the use of extended Hückel theory to describe the system. Marchi and Chandler ${ }^{19}$ also studied the $\mathrm{Fe}^{+2 /+3}$ selfexchange reaction, using path-integral techniques with a pseudopotential description for the $\mathrm{Fe}$ and waters. They found no evidence for superexchange enhancement of the electronic coupling. More recently, Nitzan and co-workers $^{21(\mathrm{a})}$ examined et between parallel plate electrodes through water, using a pseudopotential to describe the water. They thermally equilibrated the solvent and calculated tunneling probabilities as a function of solvent configuration, assume that the solvent positions are frozen on the time scale of the tunneling event. Their results suggest that tunneling is actually reduced by the presence of solvent, and that the tunneling depends strongly on the orientation of the solvent molecules between the two electrodes. The latter two studies used one-electron treatments, which the above results suggest, will lead to a less accurate description of the electronic coupling in water (i.e., holelike superexhange is neglected). This surely accounts for some of the differences between our results and theirs, but it is also possible that our results are affected by the limited number of solvent molecules included in the calculations. To address this question further we are currently investigating use of semi-empirical methods coupled to molecular dynamics to calculate thermally averaged in-solvent electronic coupling elements, with significantly larger numbers of solvent molecules (20-60) included in the GMH calculation of $H_{a b} \cdot{ }^{36}$

\section{CONCLUSIONS}

Results are presented that address the size, orientation dependence, and distance dependence of the electronic coupling element in $e t$ mediated by a variety of solvent species. It is found that the solvent effect on the electronic coupling is strongly dependent on the identity of the solvent, as well as 
the $D / A$ orbitals involved in the et process. However, for water and ammonia the electronic coupling element connecting $D$ and $A$ states is found to depend weakly on the orientation of the solvent molecule(s). The data also qualitatively support the Condon approximation.

\section{ACKNOWLEDGMENTS}

The authors gratefully acknowledge helpful discussions with Dr. Marshall Newton and helpful comments from the referee. Financial support of this research was provided by the Camille and Henry Dreyfus foundation, through a Camille and Henry Dreyfus teacher-Scholar award (R.J.C., 19931998), the National Science Foundation (CHE-9731634) and the donors of the Petroleum Research Fund. The computations were performed on the Harvey Mudd College Computational Chemistry Facility, the establishment of which was made possible by a grant from the National Science Foundation, (CHE-9512467).

${ }^{1}$ R. A. Marcus and N. Sutin, Biochim. Biophys. Acta 811, 265 (1985).

${ }^{2}$ R. A. Marcus, in Light Induced Charge Separation in Biology and Chemistry, edited by H. Gerischer and J. J. Katz (Dahlem, Berlin, 1979), p. 15.

${ }^{3}$ M. D. Newton and N. Sutin, Annu. Rev. Phys. Chem. 35, 437 (1984).

${ }^{4}$ P. F. Barbara, T. J. Meyer, and M. A. Ratner, J. Phys. Chem. 100, 13148 (1996).

${ }^{5}$ R. A. Marcus, J. Chem. Phys. 43, 679 (1965), and references cited therein.

${ }^{6}$ N. S. Hush, Trans. Faraday Soc. 57, 557 (1961).

${ }^{7}$ V. G. Levich and R. R. Dogonadze, Collect. Czech. Chem. Commun. 26, 193 (1961)

${ }^{8}$ N. R. Kestner, J. Logan, and J. Jortner, J. Phys. Chem. 78, 2148 (1974).

${ }^{9}$ D. F. Calef and P. G. Wolynes, J. Phys. Chem. 87, 3387 (1983).

${ }^{10}$ L. D. Zusman, Chem. Phys. 49, 295 (1980).

${ }^{11}$ J. Jortner and M. Bixon, J. Chem. Phys. 88, 167 (1988).

${ }^{12}$ M. J. Weaver, Chem. Rev. 92, 463 (1992).

${ }^{13}$ (a) J. R. Miller, J. Phys. Chem. 82, 767 (1978); (b) J. R. Miller and J. V. Beitz, J. Chem. Phys. 74, 6746 (1981); (c) J. R. Miller, J. Phys. Chem. 79, 1070 (1975).

${ }^{14}$ R. J. Cave, M. D. Newton, K. Kumar, and M. B. Zimmt, J. Phys. Chem. 99, 17501 (1995).

${ }^{15}$ M. D. Newton and R. J. Cave, in Molecular Electronics, edited by M. A. Ratner and J. Jortner (IUPAC, London, 1996), p. 73.

${ }^{16}$ (a) K. Kumar, Z. Lin, D. H. Waldeck, and M. B. Zimmt, J. Am. Chem. Soc. 118, 243 (1996); (b) K. Kumar, I. V. Kurnikov, D. N. Beratan, D. H. Waldeck, and M. B. Zimmt, J. Phys. Chem. A 102, 5529 (1998).

${ }^{17}$ I. R. Gould, R. H. Young, L. J. Mueller, A. C. Albrecht, and S. Farid, J. Am. Chem. Soc. 116, 3147 (1994); 116, 8188 (1994).

${ }^{18}$ (a) K. D. Jordan and M. N. Paddon-Row, J. Phys. Chem. 96, 1188 (1992); (b) K. Kim, K. D. Jordan, and M. N. Paddon-Row, ibid. 98, 11053 (1994); (c) K. D. Jordan, D. Nachtigallova, and M. N. Paddon-Row, in Modern Electronic Structure Theory and Applications in Organic Chemistry, edited by E. R. Davidson (World Scientific, New Jersey, 1997), p. 257.

${ }^{19}$ M. Marchi and D. Chandler, J. Chem. Phys. 95, 889 (1991).

${ }^{20}$ S. Larsson, J. Phys. Chem. 88, 1321 (1984).

${ }^{21}$ (a) A. Mosyak, A. Nitzan, and R. Kosloff, J. Chem. Phys. 104, 1549 (1996); (b) I. Benjamin, D. Evans, and A. Nitzan, ibid. 106, 1291, 6647 (1997).

${ }^{22}$ M. D. Newton, Chem. Rev. 91, 767 (1991).

${ }^{23}$ J. Halpern and L. E. Orgel, Discuss. Faraday Soc. 29, 32 (1960).

${ }^{24}$ H. M. McConnell, J. Chem. Phys. 35, 508 (1961).

${ }^{25}$ S. Larsson, J. Am. Chem. Soc. 103, 4034 (1981).

${ }^{26}$ (a) C. Liang and M. D. Newton, J. Phys. Chem. 96, 2855 (1992); (b) 97, 3199 (1993).
${ }^{27}$ L. A. Curtiss, C. A. Naleway, and J. R. Miller, J. Phys. Chem. 99, 1182 (1995).

${ }^{28}$ (a) J. N. Onuchic and D. N. Beratan, J. Chem. Phys. 92, 722 (1990); (b) J. J. Regan, S. M. Risser, D. N. Beratan, and J. N. Onuchic, J. Phys. Chem. 97, 13083 (1993).

${ }^{29}$ P. Siddarth and R. A. Marcus, J. Phys. Chem. 96, 3213 (1992).

${ }^{30}$ (a) A. A. Stuchebrukhov, Chem. Phys. Lett. 225, 55 (1994); (b) A. A. Stuchebrukhov and X. Song, J. Chem. Phys. 101, 9354 (1994).

${ }^{31}$ (a) M. Braga and S. Larsson, Chem. Phys. Lett. 213, 217 (1993); (b) M. Braga, A. Broo, and S. Larsson, Chem. Phys. 156, 1 (1991).

${ }^{32}$ M. Braga and S. Larsson, J. Phys. Chem. 97, 8929 (1993).

${ }^{33}$ B. S. Brunschwig, J. Logan, M. D. Newton, and N. Sutin, J. Am. Chem. Soc. 102, 5798 (1980).

${ }^{34}$ (a) L. Landau, Phys. Z. Sowjetunion 2, 46 (1932); (b) C. Zener, Proc. R. Soc. London, Ser. A 137, 696 (1932); 140, 660 (1933).

${ }^{35}$ J. N. Onuchic, D. N. Beratan, and J. J. Hopfield, J. Phys. Chem. 90, 3707 (1986).

${ }^{36}$ N. E. Miller, M. C. Wander, and R. J. Cave, J. Phys. Chem. A (submitted).

${ }^{37}$ R. J. Cave and M. D. Newton, J. Chem. Phys. 106, 9213 (1997).

${ }^{38}$ R. J. Cave and M. D. Newton, Chem. Phys. Lett. 249, 15 (1996).

${ }^{39}$ R. J. Cave, D. V. Baxter, W. A. Goddard III, and J. D. Baldeschwieler, J. Chem. Phys. 87, 926 (1987).

${ }^{40}$ (a) T. Pacher, L. S. Cederbaum, and H. Köppel, J. Chem. Phys. 89, 7367 (1988); (b) L. S. Cederbaum, J. Schirmer, and H.-D. Meyer, J. Phys. A 22, 2427 (1989); (c) T. Pacher, H. Köppel, and L. S. Cederbaum, J. Chem. Phys. 95, 6668 (1991); (d) T. Pacher, L. S. Cederbaum, and H. Köppel, Adv. Chem. Phys. 84, 293 (1993); (e) W. Domcke and C. Woywood, Chem. Phys. Lett. 216, 362 (1993); (f) W. Domcke, C. Woywood, and M. Stengle, ibid. 226, 257 (1994).

${ }^{41}$ B. O. Roos, Adv. Chem. Phys. 69, 399 (1987).

${ }^{42}$ MOLCAS, version 3, K. Andersson, M. P. Fülscher, G. Karlström, R. Lindh, P.-Ä. Malmqvist, J. Olsen, B. O. Roos, and A. J. Sadlej, University of Lund, Sweden, M. R. A. Blomberg and P. E. M. Siegbahn. University of Stockholm, Sweden, V. Kellö, J. Noga, and M. Urban, Caimans University, Slovakia, and P.-O. Widmark, IBM Sweden, 1994.

${ }^{43}$ A. J. H. Wachters, J. Chem. Phys. 52, 1033 (1970).

${ }^{44}$ R. C. Raffenetti, J. Chem. Phys. 58, 4452 (1973).

${ }^{45}$ M. W. Schmidt and K. Ruedenberg, J. Chem. Phys. 71, 3951 (1979).

${ }^{46}$ (a) P.-O. Widmark, P.-A. Malmqvist, and B. O. Roos, Theor. Chim. Acta 77, 291 (1990); (b) P.-O. Widmark, B. J. Persson, and B. O. Roos, ibid. 79, 419 (1991).

${ }^{47}$ W. S. Benedict, N. Gailer, and E. K. Pyler, J. Chem. Phys. 24, 1139 (1956).

${ }^{48}$ W. S. Benedict and E. K. Pyler, Can. J. Phys. 35, 1235 (1957).

${ }^{49}$ L. A. Curtiss, C. A. Naleway, and J. R. Miller, J. Phys. Chem. 97, 4050 (1993).

${ }^{50}$ S. F. Boys and F. B. Bernardi, Mol. Phys. 19, 553 (1970).

${ }^{51}$ M. J. Frisch, J. E. DelBene, J. S. Binley, and H. F. Schaefer III, J. Chem. Phys. 84, 2279 (1986).

${ }^{52}$ (a) R. S. Mulliken, J. Am. Chem. Soc. 64, 811 (1952); (b) R. S. Mulliken and W. B. Person, Molecular Complexes (Wiley, New York, 1969); (c) N. S. Hush, Prog. Inorg. Chem. 8, 391 (1967); (d) N. S. Hush, Electrochim. Acta 13, 1005 (1968); (e) J. R. Reimers and N. S. Hush, J. Phys. Chem. 95, 9773 (1991); (f) C. Creutz, M. D. Newton, and N. Sutin, J. Photochem. Photobiol., A 82, 47 (1994).

${ }^{53}$ Where it is not specified by symmetry the GMH method employs the component of each dipole vector in the direction of the dipole difference vector for the initial and final states (two-state case) or the average of such differences when several $e t$ processes are considered for a given system.

${ }^{54}$ H. S. Green, in Encyclopedia of Physics, Vol. X, edited by S. Flügge (Springer, Berlin, 1960), p. 1.

${ }^{55}$ Handbook of Chemistry and Physics, 65th ed. (Chemical Rubber Company, Boca Raton, Florida 1984).

${ }^{56}$ E. N. Heifets, I. Daizadeh, J. Guo, and A. A. Stuchebrukhov, J. Phys. Chem. A 102, 2847 (1998).

${ }^{57}$ K. G. Spears, X. Wen, and S. M. Arrivo, J. Phys. Chem. 98, 9693 (1994). 